\title{
A Job Task Analysis for Technicians in the Offshore Wind Industry
}

\author{
Gemma S. Milligan*, Joseph P. O’Halloran and Michael J. Tipton \\ Extreme Environments Laboratory, Department of Sport and Exercise Science, \\ University of Portsmouth, Portsmouth, UK
}

\begin{abstract}
.
BACKGROUND: To establish whether an organization has a valid Physical Employment Standard (PES), it is important to determine those aspects of the job that are critical to operational success.

OBJECTIVE: To determine the tasks of the Offshore Wind Industry (OWI) and whether the ability to undertake these tasks is adequately assessed.

METHODS: The task analysis was completed through: observations; the research team undertaking tasks; reviewing operational manuals; and focus groups. In addition, a review of existing PES for the OWI was completed to determine whether standards matched with the results of the task analysis.

RESULTS: Five critical tasks were identified: transfer from the vessel to the Transition Piece; ascent of the internal ladder; manoeuvre through hatches; torque and tensioning; and hauling a casualty up the tower. With the exception of aerobic capacity, the physical components required by Technicians are not assessed by the current medical standards, nor are these assessments standardized across companies.

CONCLUSIONS: The Job Task Analysis undertaken can be used to inform decisions regarding the physical fitness requirements (selection), assessments and training of Technicians, with a view to ensuring that they are physically capable of undertaking the critical tasks without undue risk of injury to themselves or others.
\end{abstract}

Keywords: Subject matter experts, wind technicians, physically demanding tasks, ladder climbing

\section{Introduction}

Since 2003 there has been a large-scale commercial development of offshore wind farms [1]. The largest offshore wind farms are currently located in northern Europe, especially the UK and Germany, which together account for approximately $84 \%$ of the total offshore wind power installed worldwide [2]. When operational the turbines are serviced and maintained by Technicians who are typically responsible for:

\footnotetext{
*Address for correspondence: Gemma S. Milligan, Extreme Environments Laboratory, Department of Sport and Exercise Science, University of Portsmouth, Spinnaker Building, Cambridge Road, Portsmouth, Hants, PO1 2ER, UK. Tel.: +44 02392 845358; Fax: +44 02392 843620; E-mail: gemma.milligan@ port.ac.uk.
}

testing electrical components and systems, as well as mechanical and hydraulic systems; inspecting the exterior and physical integrity of towers; climbing towers to inspect or repair turbine equipment; collecting turbine data for testing or research and analysis; performing routine maintenance on wind turbine; and troubleshooting mechanical, hydraulic, or electrical malfunctions. With the industry in its infancy, many of the practices adopted to manage employee health and safety has been taken from the Oil and Gas Industry.

To assess an employee's physical ability to undertake their job, it is important to follow a valid methodology when developing a Physical Employment Standard (PES). In the UK, tasked-based PES 
have been introduced by the Military [3-5]; Fire and Rescue Service [6]; Maritime and Coastguard Agency [7]; Royal National Lifeboat Institution [8-10], and recommended to the Oil and Gas Industry [6]. These standards generally base the suitability for employment on the physical and physiological components associated with the safe and successful completion of tasks that are considered generic and critical, for a specific job, thus employment is free from age and sex discrimination [11, 12]. The critical tasks are identified through a Job Task Analysis (JTA) which evaluates an occupation to determine the frequency, importance and physical demand of the tasks involved [13-16]. A PES can include measures of strength, endurance, anthropometrics, flexibility, motor skills and cardiovascular and metabolic fitness. These are most commonly assessed through either direct task simulations of the job or predictive tests, [4-6, 8-10, 14, 17, 18].

The aim of this study was to undertake a JTA for Technicians performing maintenance tasks of operational turbines, in the Offshore Wind Industry (OWI). In addition, the validity of the current technician medical fitness tests were reviewed.

\section{Methods}

\subsection{Job Task Analysis}

The JTA in the present study was applied to Technicians working on operational turbines and did not apply to employees associated with turbine construction. The terminology used throughout the JTA was based on the Fig. 1.

The physically demanding tasks undertaken by Technicians in the OWI during a typical working day and in emergency situations were broken down into component jobs which were then described in terms of: frequency, duration, rest breaks, clothing ensembles, environmental conditions and the methods of best practice (MOBP). The JTA was completed by: observations of Technicians performing tasks; the research team undertaking tasks; reviewing operational manuals; the measurement of equipment mass and/or dimensions; and a focus group with an expert panel. The expert panel comprised of nine members of the offshore wind industry, who all have various experiences and job roles (Table 1). The Subject Matter Expert (SMEs) fulfilled at least one of the seven criteria detailed in Table 2. Collectively, the nine SMEs fulfilled all seven criteria.

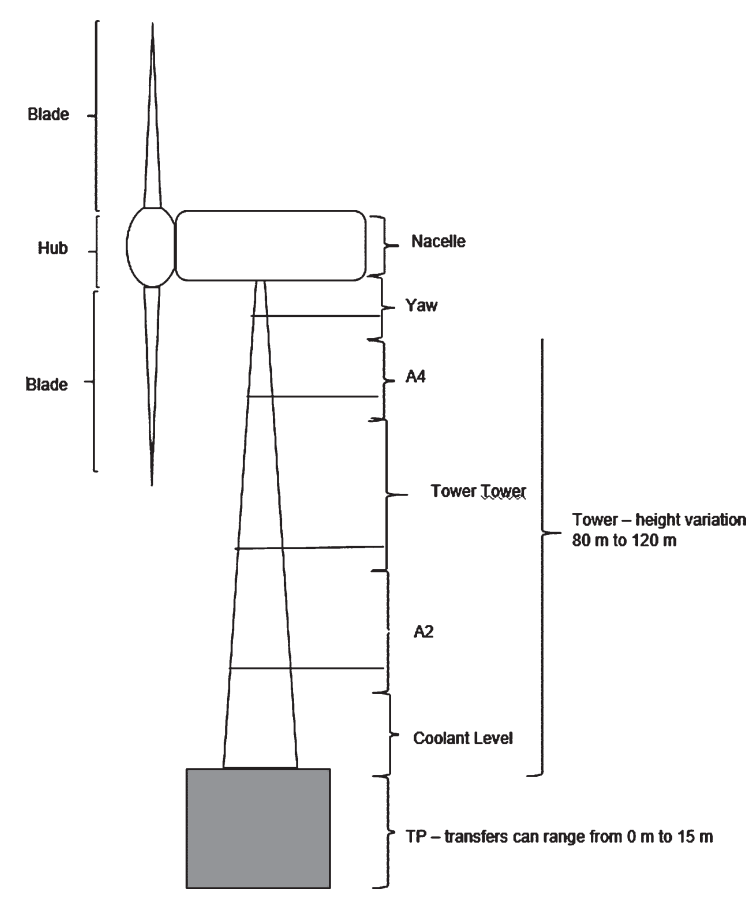

Fig. 1. Schematic of an offshore wind turbine. The schematic is not to scale with variations occurring in all aspects across the industry. The model is based on a 3.6 Offshore Turbine.

The results of the Job Task Analysis were sent to the G+ committee (which consists of representative for each of the member Offshore Wind Organizations) for comment and endorsement.

Critical tasks included the most physically demanding activities associated with two groups of Technicians, these were Service Teams (on average these teams are made up of three Technicians [range 2 to 4], of which one will be a Team Leader) and Troubleshooting Teams (two Technicians).

\subsection{Review of the current PES for offshore wind technicians}

Five companies from G+ responded to an email asking if any internal fitness standards/tests were implemented within their organization. Companies were asked: What these tests are? What are the pass scores? Where do these data came from?

\section{Results}

\subsection{Job Task Analysis}

A detailed qualitative description of the tasks associated with the OWI are presented. 
Table 1

Demographics of the nine subject matter experts

\begin{tabular}{lcccc}
\hline Job Title & $\begin{array}{c}\text { Years in the } \\
\text { industry }\end{array}$ & $\begin{array}{c}\text { Years working } \\
\text { as a technician }\end{array}$ & Age & Sex \\
\hline $\begin{array}{l}\text { Head of HSE* Offshore } \\
\quad \text { Technologies \& Wind }\end{array}$ & 20 & n/a & 47 & Male \\
$\quad$ Construction & & & 44 & Male \\
Shift manager & 8 & 4 & 23 & Female \\
Site technician wind power & 6.5 & 4.5 & 51 & Female \\
HSE* Advisor Wind Generation & 8 & - & 50 & Male \\
Vessel Master & 4 & - & 32 & Female \\
Offshore operational engineer & 8 & - & 45 & Male \\
QHSE* Safety Advisor & 7 & 7 & 43 & Male \\
Senior Technician & 7 & 5 & 36 & Male \\
Authorising Officer & & & & \\
\hline
\end{tabular}

${ }^{*} \mathrm{HSE}=$ Health Safety and Environment; QHSE = Quality, Health, Safety, and Environment.

Table 2

Criteria for Subject Matter Experts adapted from Blacklock et al. [19]

Criteria
1. Experience performing the task onshore
2. Experience performing the task offshore
3. Experience performing the task during an emergency situation
4. Experience in a position of leadership where you have directed other employees to perform
the task and have observed the task being performed
5. Have witnessed the task being performed in an acceptable manner
6. Have witnessed the task being performed unsuccessfully and can attest to the reasons for, and
the consequences of, this failure (e.g. A person was not fit enough to climb the ladder)
7. Witnessed and/or performing the task using several techniques and can comment on the
advantages and disadvantages of these techniques

Table 3

Example shift patterns provided by the subject matter experts

\begin{tabular}{lcl}
\hline \multicolumn{2}{c}{ Shift Pattern } & Employee Type \\
\cline { 1 - 3 } Days On & Days off & \\
\hline 4 & 4 & Organisational employee \\
6 & 3 & Site based \\
14 & 7 & Travelling technician (contractor) \\
7 & 7 & $\begin{array}{l}\text { Organisational employee, Site based } \\
\text { and Contractors }\end{array}$ \\
14 & 14 & $\begin{array}{c}\text { Technicians living on board a vessel } \\
\text { - deep water fields }\end{array}$ \\
\hline
\end{tabular}

\subsubsection{An overview of shift patterns and the working day}

The majority of operational servicing and maintenance work is carried out March to September, with a reduced number of Technicians working during the winter months of October to February. A number of different shift patterns are implemented across the industry (Table 3). During these shift patterns "bad weather days" could mean Technicians go through periods of not working. Some organizations automatically stand Technicians down after 9 days of continuous work and Technicians can stand themselves down if feeling excessively fatigued.
The start of the working day is often tide dependent and varies throughout the shift pattern, e.g. departure time may vary between 0300 and 1500 . In general, all Technicians work a 12-hour day, which can be spent on one turbine or changing between turbines on up to three transfers.

\subsubsection{The tasks}

Based on the qualitative analysis undertaken five tasks were deemed to be the critical for Technicians in the OWI, these are: transfer from the vessel to the transition piece (TP); ascent of the internal ladders; manoeuvre through hatches; torque and tensioning; and hauling a casualty up the tower. A summary of the critical tasks are detailed in Table 4, with full descriptions provided in the following sections.

3.1.2.1. Transfer from the vessel to the turbine. The time taken to travel between the port and turbine can vary depending on the; distance of the field from the port; weather conditions; the number of Technicians aboard (up to 12 Technicians); sea state and sickness (if vomiting is reported, a vessel will return to port). Therefore, the transfer of Technicians can take 3 to 4 hours. 


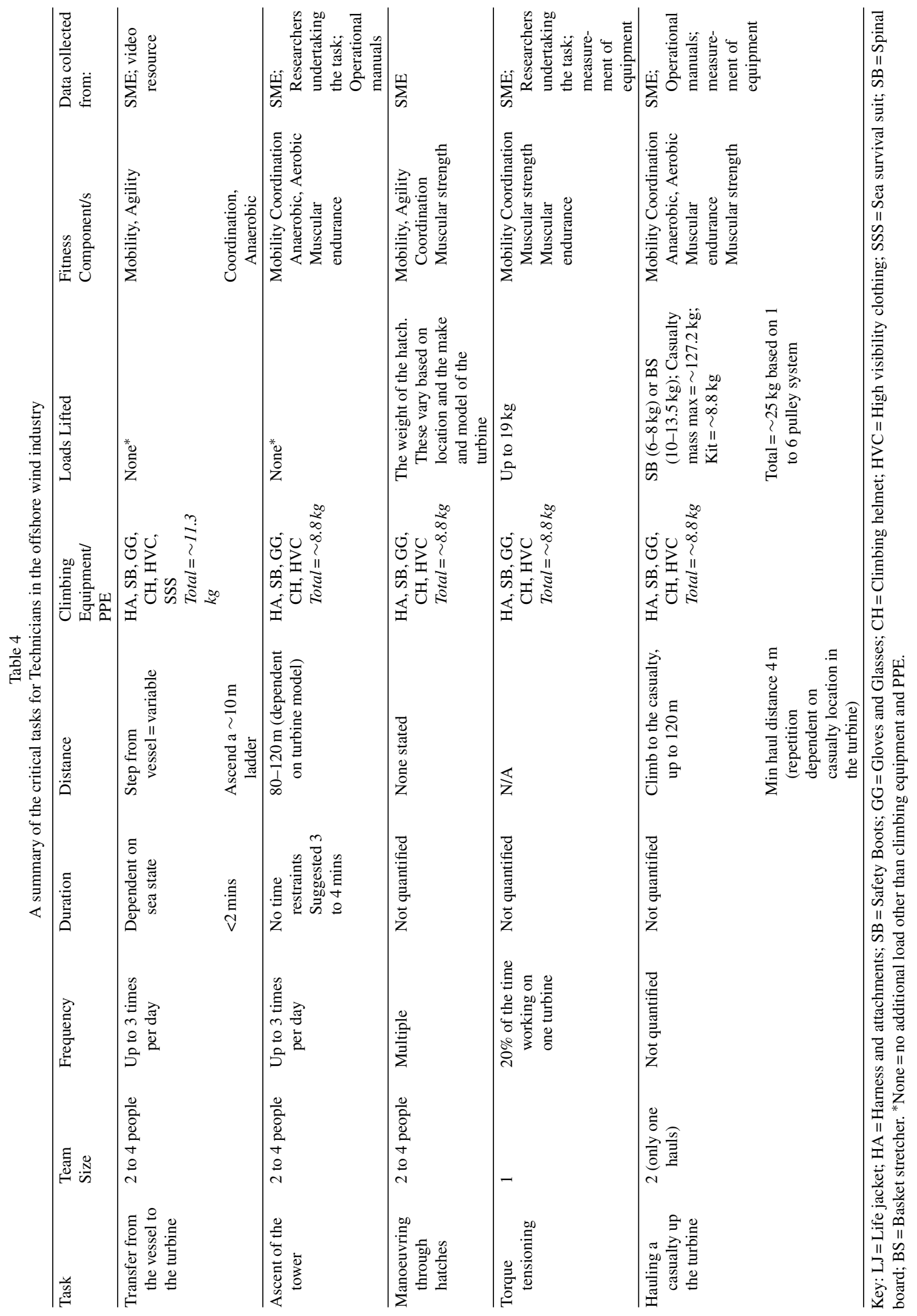




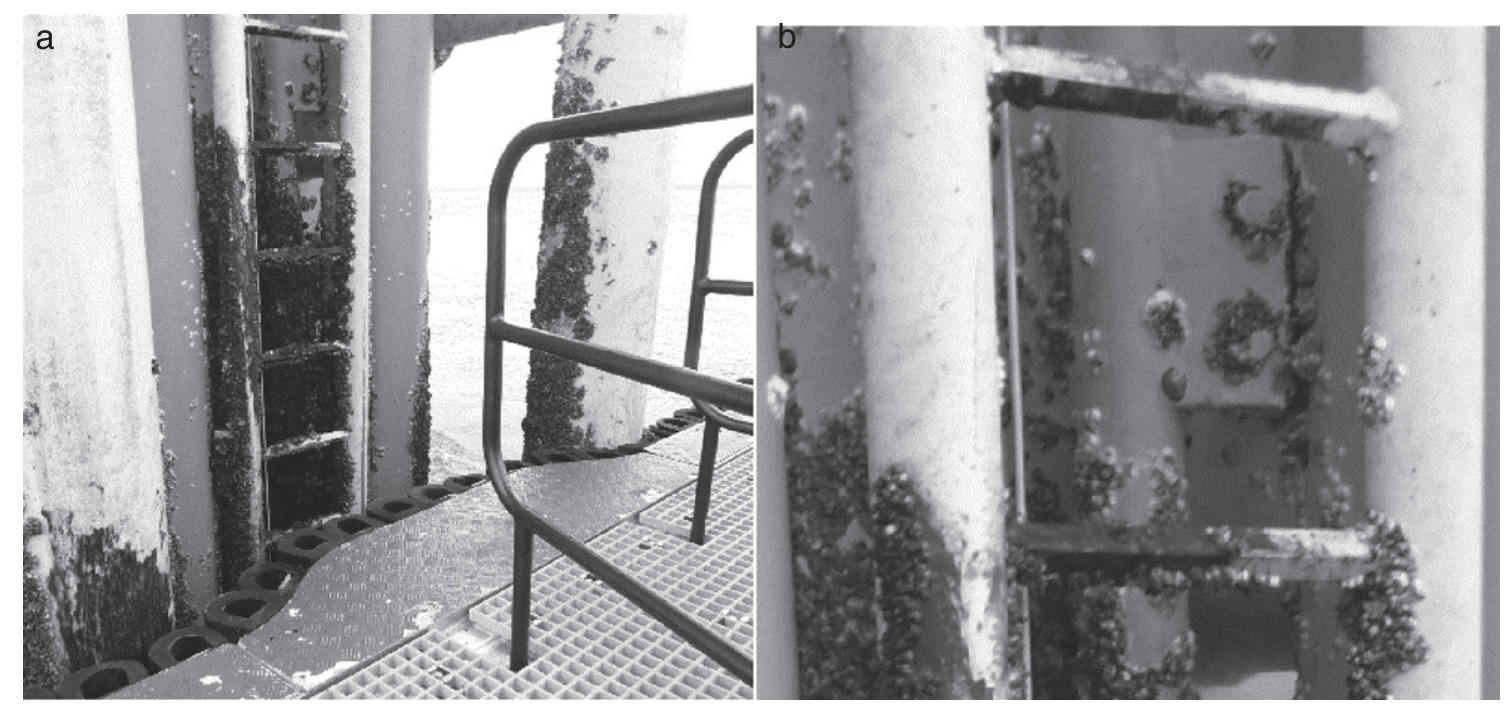

Fig. 2a \& 2b. Examples of the external ladder on a turbine. NB. Figure 2a depicts a vessel up against an external ladder.

Once the vessel arrives at the turbine there are serval transfer methods from the vessel onto the turbine, these are dependent on the design and location of the turbine. The SMEs stated the most physically demanding method requires Technicians to transfer from the vessel to the TP (Figs. $1 \& 2$ ) via an external vertical ladder, wearing: a lifejacket $(\sim 2.3 \mathrm{~kg})$, personal protective equipment ([PPE] safety boots, gloves, glasses, climbing helmet $[\sim 0.5 \mathrm{~kg}]$ ), high visibility clothing, harness and attachments $(\sim 6 \mathrm{~kg})$, and potentially a sea survival suit $(\sim 2.5 \mathrm{~kg})$.

Technicians step from the vessel onto the external ladder. Sea state and thus the movement of the vessel affects: the size of the initial step onto the ladder; the speed Technicians step from the vessel to the external ladder and distance the Technicians will have to climb up the external ladder. SMEs reported that these component tasks require coordination and agilility. Technicians must be able to achieve hip flexion past $90^{\circ}$ to transfer onto the external vertical ladders, this highlight a need for hip mobility. The rungs of the ladder are typically diamond shaped (each side of the diamond shaped rung $=40 \mathrm{~mm}$ ) with $330 \mathrm{~mm}$ between each rung (mid-point to rung mid-point), $500 \mathrm{~mm}$ internal width (to the inside of the vertical rail) and $680 \mathrm{~mm}$ external width (to the outside of the vertical rail; Fig. 2). The duration of the initial climb onto the TP was estimated by the SME groups to take no more than 2 minutes and is proceeded by a rest. The procedures described are reversed when disembarking the TP onto the vessel.
The condition of the ladder rungs (i.e. build-up of deposits and wet rungs); feelings of seasickness; the clothing worn (i.e. a sea survival suit restricting movement); previous climbs (i.e. fatigue); and light conditions, will in addition, affect the nature and demand of the transfer onto the external ladder.

\subsubsection{Climbing the tower and maneuvering} through hatches. The total height from the TP to Nacelle ranges from $80 \mathrm{~m}$ to $120 \mathrm{~m}$ (Fig. 1). Depending on the make and model of turbine, SMEs estimated that there could be between 5 to 10 ladders of varying height between the climb from TP to the Nacelle.

Generally, the internal ladders have an internal width of $400 \mathrm{~mm}$; external width of $470 \mathrm{~mm}$, with $300 \mathrm{~mm}$ between rungs (mid-point to rung midpoint), but may vary depending on the make and model of turbine.

Prior to the Nacelle ascent, teams typically rest for a minimum of 10 minutes. During the ascent one Team member will climb a ladder at a time, this technician will be wearing full PPE and a climbing harness attached to a safety line and/or a fall arrest. The SMEs reported that whilst one of the Team is climbing the other team members are resting. There are no time constraints placed on a Team ascending the tower, and they can rest either at the points between ladders or whilst climbing. The intermittent nature of this task might suggest that the task could require both the aerobic and anaerobic energy sys- 
tems. The SMEs stated that the MOBP for climbing the ladder was with two points of contact (e.g. using and alternate hand to foot action), this was proposed to be easier and more efficient and require Technicians to be coordinated, agile and mobile.

Operationally, the SMEs stated the Lead Technician climbs to Level A2 (approx. $10 \mathrm{~m}$ ), whilst the other two Technicians would climb straight to Tower Tower (approx. $30 \mathrm{~m}$, Fig. 1), which would take 3 to 4 minutes, suggesting climbing rates between 25 rungs. $\min ^{-1}$ to 33 rungs. $\mathrm{min}^{-1}$. Technicians tend to rest on reaching Tower Tower, until the second and/or third technician has reached this level. SMEs reported a significant fatigue in the forearms approximately $3 / 4$ of the way up the Tower Tower, which suggested a requirement for local muscular endurance. The number of rests on the ladder increases, and climbing rate decreases to $\sim 20$ rungs. $\mathrm{min}^{-1}$ as the climb progresses up past A4 to the Yaw and into the Nacelle.

Movement through hatches is a critical task when ascending the turbine. Hatches vary in size, orientation and mass within a turbine and across turbines, depending on the make and model (these were not quantified at the time and SME were unable to provide estimations), thus Technicians are required to adopt various positions when opening and ascending hatches that require strength, mobility, agility and coordination.

On reaching the Nacelle, teams have a minimum of 10 minutes' rest before beginning the other physically demanding tasks. The number of complete ascents and descents of the Tower varies from one to three over the course of the day.

\subsubsection{Torque and tensioning. The SMEs reported} that the most physically demanding task Service Teams were required to complete was bolt torque and tensioning, which forms approximately $20 \%$ of a turbine service time. Service Technicians manually handle the tensions heads used to tighten bolts of various weights, in a variety of awkward positions whilst standing, kneeling or seated, depending on the dimensions of the work space, suggesting the requirement of mobility. The heaviest torque wrench used was measured at $7 \mathrm{~kg}$ and the heaviest tension head $19 \mathrm{~kg}$ (Table 4). SMEs stated this was a whole body task, with fatigue accumulating in the shoulders, torso and lower back indicating a need for muscular strength and endurance.

3.1.2.4. Hauling a casualty up the turbine. In an emergency situation, the most physical demanding casualty evacuation was identified by SMEs as hauling a casualty up to the top of the turbine for extraction from the helipad. The Technicians are required to climb (without rest) to where the casualty is located, this could be the top of the turbine and therefore would require a straight ascent of the tower. This suggests a requirement for a higher level of aerobic and anaerobic fitness than those ascending the turbine under non-emergency situations.

Upon reaching the casualty, Technicians must manual handling them into a stretcher and haul the casualty up the turbine for extraction from the helipad. The manual hauling method for this task is a 6 to 1 pulley, supported by work positioners that have a reach of $4 \mathrm{~m}$. Therefore, the minimum distance Technicians would be expected to haul a casualty is $4 \mathrm{~m}$, although in some cases this would have to be repeated multiple times.

Casualty mass is limited by the maximum load the climbing kit can withstand i.e. $136 \mathrm{~kg}$ (casualty plus PPE), not including the spinal board [approx. $6 \mathrm{~kg}$ to $8 \mathrm{~kg}$ ] and/or basket stretcher [approx. $10 \mathrm{~kg}$ to $13.5 \mathrm{~kg}]$ ). The need to haul these loads repeatedly will require muscular strength, endurance and coordination.

\subsubsection{Other physically demanding tasks. Four} tasks that occur during each shift are: manual handling of loads up to $27 \mathrm{~kg}$ in a single person lift up to a height of $1 \mathrm{~m}$; manipulation of loads on a crane; operation of brake calipers in the Yaw and fixing lights on a ladder at various angles. The SMEs subjectively reported that the physical demands of these tasks did not supersede those documented above.

\subsection{The current PES for offshore wind technicians}

Five OWI organizations stated that they applied one of two off the shelf medical policy documents [20, 21], which assess the two fitness parameters of aerobic fitness (Table 6) and a subjectively rated assessment of mobility. Currently, all five organizations implement medical standards as opposed to a PES.

Two different aerobic standards are presently used by the five organizations. These include an aerobic standard where the pass mark is a predicted oxygen uptake of $35 \mathrm{~mL} \cdot \mathrm{kg}^{-1} \cdot \mathrm{min}^{-1}$ or a pass of "good", as stipulated by the normative data of the Chester Step Test. The aerobic standard of $35 \mathrm{~mL} \cdot \mathrm{kg}^{-1} \cdot \mathrm{min}^{-1}$ derived from the Oil and Gas Industries [22] recommendation for Emergency Response Teams (ERT). 
Table 5

Tension heads and lifting requirements

\begin{tabular}{|c|c|}
\hline $\begin{array}{l}\text { Tension head } \\
\text { mass }(\mathrm{kg})\end{array}$ & Lifting requirement \\
\hline$\overline{8.5}$ & The $8.5 \mathrm{~kg}$ and $9 \mathrm{~kg}$ tension heads are often used in line with the shoulder (approx. $1.6 \mathrm{~m}$ ). \\
\hline 9 & This can often require the tension head to be held in a single hand. \\
\hline 13 & $\begin{array}{l}\text { Generally used horizontally from chest height (approx. } 1.5 \mathrm{~m} \text { ). This can sometimes require } \\
\text { the tension head to be held in a single hand. }\end{array}$ \\
\hline 19 & $\begin{array}{l}\text { These are predominantly used at the Tower Tower section (Fig. 1) of the turbine. The } \\
\text { tension head is normally lifted to chest height, using an upright row movement. }\end{array}$ \\
\hline
\end{tabular}

Table 6

Overview of the current medical from the five respondents

\begin{tabular}{llc}
\hline Organisation & $\begin{array}{l}\text { Standard and test used to } \\
\text { assess fitness }\end{array}$ & Level/Pass criteria \\
\hline 1 & Oil \& Gas Offshore & \\
& Medical - Chester Step & \\
test & \\
2 & Chester Step test & \\
3 & Renewables UK: Medical & Not reported \\
& Fitness to Work - Wind & \\
& Turbines - Chester & \\
& Step test & \\
4 & Oil \& Gas Offshore & Level "Good" \\
& Medical - Chester Step & \\
& test & \\
5 & Oil \& Gas Offshore & N/A \\
& Medical - no aerobic & \\
& test \\
\hline
\end{tabular}

\section{Discussion}

This is the first study to identify tasks considered physically demanding and critical for Technicians working in the OWI. Five critical tasks were identified: transfer from the vessel to the TP; ascent of the internal ladder; manoeuvre through hatches; torque and tensioning; and hauling a casualty up the tower. It is proposed that the identified tasks require a range of physical attributes including: mobility, upper and lower limb strength, strength-endurance, aerobic and anaerobic capacity (Table 5).

The critical task of ladder climbing yielded conflicting results regarding the MOBP. SMEs reported that Technicians climb a ladder with two points of contact, this is in contrast to the directive for the Health and Safety Executive (HSE) guideline for the safe use of step ladders and ladders, which advocates three points of contact [23]. It should be noted that this guideline appears to be for those free climbing, not those attached to a fall arrest harness. Similarly, the "Good practice Guideline for Working at Height in the Offshore Wind Industry" [24] states "the probability of falling can be minimized by limiting the activities that are carried out from a ladder, and ensur- ing that users maintain three points of contact with the ladder". Therefore, the MOBP used by Technicians to climb ladders requires further investigation. In order to quantify the physical demands of the critical tasks the OWI would need to agree minimum acceptable operating procedures and MOBP for tasks where the load and repetitions could not be quantified objectively [11].

It was not possible to determine the MOBP or minimum performance standards for all tasks presented. For example, due to variations in turbines, standardizing certain tasks such as the transfer from the vessel is extremely difficult. Further analysis that was beyond the scope of this project would be required to assess: the impact various ladder conditions, brought about by the environment, (e.g. wet slippery rungs) on the demands of transferring from the vessel to the; the impact of sea state on the physical requirements required to transfer onto the ladder; orientations and forces required to lift hatches. Torque tensioning is a common manual handling task and as such would fall under the Health and Safety Executive (HSE) guidelines on "Getting to grips with manual handling" [25] and Rapid Entire Body Assessment (REBA) [26], which would ultimately set the performance standards from which a PES could be applied.

Currently assessments of fitness are prescribed within medical standards, where the focus is to assess health rather than the physical ability of Technicians to undertake the jobs of the OWI. The tests within these medical standards include a simple step test to predict maximal aerobic capacity ( $\left.\dot{V} \mathrm{O}_{2} \max \right)$ and subjective range of movement tests. In some instances, Offshore Wind Organizations adopt the Oil and Gas UK Medical standards that set a minimum predicted $\dot{V} \mathrm{O}_{2}$ max requirement of $35 \mathrm{~mL} \cdot \mathrm{kg}^{-1} \cdot \mathrm{min}^{-1}$, based on the critical task of ladder climbing in the Oil and Gas industry [22]. Whilst those working in the Oil and Gas Industry may be required to undertake a critical task such as ladder climbing, the performance of this task, the duration, rate and clothing ensembles worn are different from 
that of Technicians in the OWI. Thus, the problem with using the Oil and Gas industry pass score is that is lacks content validity [12]. An alternative approach adopted in the RenewableUK Medical Fitness to Work suggests an aerobic capacity pass/fail recommendation based on normative data that estimated aerobic capacity in those working on wind turbines should be at least $35 \mathrm{~mL} \cdot \mathrm{kg}^{-1} \cdot \mathrm{min}^{-1}$ [27]. Basing an aerobic score on normative data may highlight individuals with conditions that compromise safety e.g. a risk of falling or sudden incapacity. However, it does not necessarily ensure capability for regular climbing of vertical ladders and for working in hot and/or confined spaces. These are yet to be quantified and could exceed what is the population norm. This would require further investigation to fully understand the physical requirements of self-paced ladder climbing, if a minimum operational standard for climbing ladders could not be agreed within the OWI.

Finally, some organizations stated they applied a score of "good", on a predictive step test, meaning based on the error of the test that an employees' actual aerobic capacity could range from $33 \mathrm{~mL} \cdot \mathrm{kg}^{-1} \cdot \mathrm{min}^{-1}$ to $59 \mathrm{~mL} \cdot \mathrm{kg}^{-1} \cdot \mathrm{min}^{-1}$. Whilst this is acceptable for health-based screening, it does not necessarily ensure that employees have the required aerobic fitness to successfully undertake the critical tasks of a technician. In addition, having a range of possible scores based on age and sex means that selection is both age and sex biased. For example, a "good" score for a male aged 20 to 29 results in a minimum estimated aerobic capacity of $44 \mathrm{~mL} \cdot \mathrm{kg}^{-1} \cdot \mathrm{min}^{-1}$ (range $44 \mathrm{~mL} \cdot \mathrm{kg}^{-1} \cdot \mathrm{min}^{-1}$ to $55 \mathrm{~mL} \cdot \mathrm{kg}^{-1} \cdot \mathrm{min}^{-1}$ ), whilst a female aged 40 to 49 , who may be expected to undertake the same critical task as the male, would have a minimum estimated aerobic capacity of $34 \mathrm{~mL} \cdot \mathrm{kg}^{-1} \cdot \mathrm{min}^{-1}$ (range $34 \mathrm{~mL} \cdot \mathrm{kg}^{-1} \cdot \mathrm{min}^{-1}$ to $42 \mathrm{~mL} \cdot \mathrm{kg}^{-1} \cdot \mathrm{min}^{-1}$ ) [28]. Having a standard that allows a range in test scores, such as those described above, are generally considered inappropriate in the context of developing a task-based PES, where standards are based on the physical demand of the critical tasks, thus ensuring selection is fair and unbiased [11].

The JTA undertaken can be used to inform decisions regarding the physical fitness requirements, assessments and training of Technicians, with a view of ensuring that they are physically capable of undertaking the critical tasks without undue risk of injury. Further investigation would be required to standardize the MOBP and quantify the physical demands of the critical tasks to develop a task based PES.
In order to do this the industry would need to agree minimum acceptable operating procedures for tasks in which the loads and repetitions cannot be quantified.

\section{Acknowledgments}

The authors would like to acknowledge: The Energy Institute; G+; Dan McKinley, Marcus Peters and Kate Harvey.

\section{Conflict of interest}

None to report.

\section{References}

[1] Henderson AR, Morgan C, Smith B, Sørensen HC, Barthelmie RJ, Boesmans B. Offshore wind energy in Europe-a review of the state-of-the-art. Wind Energy: An International Journal for Progress and Applications in Wind Power Conversion Technology. 2003;6(1):35-52.

[2] GWEC Global Wind 2017 report. Offshore Wind. 2017 http://gwec.net/wp-content/uploads/2018/04/offshore.pdf. Retrieved August 2018.

[3] Rayson MP, Holliman DE. Physical selection standards for the British army. Phase 4: Predictors of task performance in trained soldiers. Farnborough, United Kingdom: Defence Research Agency. 1995.

[4] Rayson M, Holliman D, Belyavin A. Development of physical selection procedures for the British Army. Phase 2: Relationship between physical performance tests and criterion tasks. Ergonomics. 2000;43(1):73-105.

[5] Allsopp AJ, Scarpello EG, Andrews S, Pethybridge RJ. Survival of the fittest? The scientific basis for the Royal Navy pre-joining fitness test. J Roy Nav Med Serv. 2003;89(1): 11-8.

[6] Siddall AG, Standage M, Stokes KA, Bilzon JL. Development of occupational fitness standards for the UK Fire and Rescue Services (FRS). Department for Health, University of Bath, Bath, UK, 2014.

[7] Milligan G. Fitness standards for the Maritime and Coastguard Agency and the oil and gas industry (Doctoral dissertation, University of Portsmouth). 2013.

[8] Reilly T, Wooler A, Tipton M. Occupational fitness standards for beach lifeguards. Phase 1: The physiological demands of beach lifeguarding. Occ Med. 2005;56(1):6-11.

[9] Reilly T, Iggleden C, Gennser M, Tipton M. Occupational fitness standards for beach lifeguards. Phase 2: The development of an easily administered fitness test. Occ Med. 2005;56(1):12-7.

[10] Reilly TJ. Fitness standards for Royal National Lifeboat Institution (RNLI) lifeboat crew (Doctoral dissertation, University of Portsmouth), 2007.

[11] Tipton MJ, Milligan GS, Reilly TJ. Physiological employment standards I. Occupational fitness standards: Objectively subjective? Eur J Appl Physiol. 2013;113(10): 2435-46. 
[12] Milligan GS, Reilly TJ, Zumbo BD, Tipton MJ. Validity and reliability of physical employment standards. Appl Physiol Nutr Metab. 2016;41(6):S83-91.

[13] Greenberg GJ, Berger RA. A model to assess one's ability to apprehend and restrain a resisting suspect in police work. J Occup Med. 1983;25(11):809-13.

[14] Anderson GS, Plecas D, Segger T. Police officer physical ability testing-Re-validating a selection criterion. Policing: An Int J Police Sci Manag. 2001;24(1):8-31.

[15] Taylor NA, Groeller H. Work-based physiological assessment of physically-demanding trades: A methodological overview. J Physiol Anthropol Appl HS. 2003;22(2):73-81.

[16] Gumieniak R, Jamnik V, Gledhill N. Physical fitness bona fide occupational requirements for safety-related physically demanding occupations; test development considerations. The Health \& Fitness J Can. 2011;4(2):47-52.

[17] Stevenson JM, Bryant JT, Andrew GM, Smith JT, French SL, Thomson JM, Deakin JM. Development of physical fitness standards for Canadian Armed Forces younger personnel. Can J Sport Sci. 1992; 17(3):214-21.

[18] Jamnik VK, Thomas SG, Shaw JA, Gledhill N. Identification and characterization of the critical physically demanding tasks encountered by correctional officers. Appl Physiol Nutr Met. 2010;35(1):45-58.

[19] Blacklock RE, Reilly TJ, Spivock M, Newton PS, Olinek SM. Standard establishment through scenarios (SETS): A new technique for occupational fitness standards. Work. 2015;52(2):375-83.
[20] Oil and Gas UK. Medical aspects of Fitness for Work Offshore: Guidance for Examining Physicians. ISBN: 978071 7665181. 2008.

[21] Renewable UK. Medical Fitnss to Work - Wind turbines: Guidelines for near offshore and land based projects. Industry report. 2013.

[22] McAtamney LY, Hignett S. REBA: Rapid entire body assessment. Appl Ergon. 2000;31:201-5.

[23] Health and Safety Executive. Safe use of ladders and stepladders: A brief guide. ISBN: 9780717665181. 2014.

[24] Oil and Gas UK. Medical aspects of Fitness for Work Offshore: Guidance for Examining Physicians. ISBN: 9780717665181.2008.

[25] Health and Safety Executive. Getting to grips with manual handling. A short guide, 2004,pp. 1-12. http://www.hse.gov. uk/pubns/indg143.pdf. Retrieved August 2018.

[26] G9 Offshore Wind Health and Safety Association. In partnership with the Energy Institute. Good practice guideline working at height in the offshore wind industry. ISBN 9780852937204. 2014.

[27] Renewable UK. Medical Fitness to Work - Wind turbines: Guidelines for near offshore and land based projects. Industry report. 2013.

[28] Sykes K, Roberts A. The Chester step test-a simple yet effective tool for the prediction of aerobic capacity. Physiotherapy. 2004;90(4):183-8. 